\title{
Salário e Relações Humanas no Trabalho
}

\author{
ENNor de Almeida Carneiro
}

(Técnico de Administração)

\section{I - "COLLECTIVE BARGAINING"}

"Collective Bargaining" é a expressão que traduz, nos Estados Unidos da América, os acôrdos coletivos de trabalho. Importante instrumento de administração de pessoal, infra-estrutura indispensável aos sistemas eficientes de relações industriais, tem constituído, naquele país, remédio eficaz contra os movimentos grevistas e a represália riefasta dos "lockouts".

a) Definição.

A barganha é uma concessão mútua, uma transação de interêsses, um acôrdo. Quando êsse acôrdo é feito por um grupo, ou em nome de um grupo, temos a barganha coletiva.

"Collective Bargaining" é locução que designa, porém, todo o processo desenvolvido para estipulação dos têrmos de um acôrdo.

Certamente a expressão poderia ser empregada em todos os lugares e ocasiões onde se firmasse uma negociação bilateral. Está consagrada, entretanto, a acepção técnica do vocábulo, para definir relações entre trabalhadores e empregadores, destinadas ao estabelecimento de condições satisfatórias de trabalho.

Como S. T. Williamsom and Herbert HaRris observam:

"There is no hard-and-fast definition for collective bargaining". (1)

b) Origens.

A idéia central dos acôrdos coletivos parte, pelo menos em tese, do pressuposto de que o trabalho humano possa ser tomado como objeto de especulação mercantil: bought and sold like goods and things". (2)

Isto pôsto, teremos que, se alguém desejar vender a sua fôrça de trabalho, pode o comprador recusar os têrmos em que a "mercadoria" é oferecida.

(1) Williamsom 86 Harris - Trends in Collective Bargaining, N. York, 1945, págs. $1-2$.

(2) "A price is offered for it, another may be asked for it, and somewhere between the two figures a price may be set upon it" - Ob. Cit., pág. 1. 
Nessa conjuntura o empregado não dispõe de prestígio suficiente para influir junto ao hipotético comprador no sentido de obrigá-lo à aceitação de determinadas condições.

Situação diferente ocorre, todavia, se diversos trabalhadores coligados colocam à venda o seu trabalho porque, nesse caso, se o empregador refutar os têrmos em que a proposta é formulada, terá pela frente dificuldades inamovíveis para o suprimento de mão-de-obra.

A situação evidentemente se agrava, para o empregador, se a união englobar todos os trabalhadores de determinada ocupação.

É, assim, através das Uniões ou Sindicatos que os trabalhadores lutam para fazer prevalecer as condições de trabalho que consideram adequadas.

Acontece, porém, algumas vêzes, que as condições de trabalho estatuídas pelas Uniões de trabalhadores são por tal forma exigentes ou absurdas, que o empregador se vê na contingência de recusá-las, sob pena de sacrificar a própria subsistência dos negócios. Eis o momento específico em que tem lugar o "collective bargaining", através do qual se ajustam divergências, na tentativa de alcançar soluções conciliatórias.

Lembra-nos, a propósito, a feliz expressão com que os autores citados, após preconizarem os acôrdos amistosos, condenam, com veemência, as tentativas, sempre infrutíferas, de imposição pela fôrça:

"... force is frequently to high a price to pay... and even victory may bring mortal wounds".

c) Harmonia no trabalho.

Em conclusão, para manter relações humanas harmoniosas no trabalho, é indispensável cooperação entre empregados e empregadores, ambos conscientes da dependência recíproca que os associa. Os acôrdos coletivos são a mesa-redonda onde se reconciliam interêsses em conflito e se firmam alianças honestas e duradouras.

E' preciso lembrar que os "collective bargainings" não devem ser encarados como simples substitutivos para o emprêgo da fôrça, porque êles representam, na realidade, muito mais do que isso. Devemos antes identificá-los como o instrumento mais adequado à obtenção de relações industriais sadias, capazes de unir trabalhadores e empregadores num regime democrático de vida e de trabalho. Os resultados obtidos através dos acôrdos coletivos, nos Estados Unidos, têm-se revelado de importância fundamental para o estabelecimento de condições pacíficas e harmoniosas de trabalho.

d) Idéias errôneas sôbre o assunto.

O público geralmente pouco sabe do resultado efetivo que decorre dos acôrdos formulados através do "collective bargaining". Geralmente despertam maior atenção os pequenos desentendimentos, sem conseqüências, que raramente ocorrem. As greves, de que o homem do povo está sempre bem informado, têm lugar cinco vêzes, em média, em cada cem acôrdos coletivos simul-

(3) Ob. cit., pág. 9 . 
tâneamente em vigor. (4) Tal percentagem é, de fato, surpreendente, e o observador inexperiente julgá-la-á fantástica. Os jornais noticiam, com riqueza de pormenores, a ocorrência esporádica de urn "lockout" ou de um movimento paredista, mas raramente ou nunca se dão conta da frequiência com que se estabelecem, nos bastidores das Emprêsas, acôrdos minuciosos, obtidos após longas, por vêzes e acaloradas, mas sempre benéficas discussões, onde firmemente se condenam tôdas as formas de "stoppage".

\section{II - BREVE FUNDAMENTAÇÃo HistóRICA E LEgAL DO "COLLECTIVE BARGAINING"}

Até aproximadamente a metade do século XIX, a única maneira que os trabalhadores conheciam de lutar pela elevação de salários ou a melhoria das condições de trabalho, consistia no gesto inamistoso e simples de abandonar as ferramentas: "to lay down the tools", como se expressa o Relatório Hoover.

No início do século em que vivemos teve lugar, nos Estados Unidos, o aparecimento das primeiras uniões de trabalhadores. Através da palavra autorizada de seus representantes faziam os empregados chegar aos patrões a garantia de que não se levantariam em greve enquanto prevalecessem na $\mathrm{Em}$ prêsa certas condições de trabalho.

Ainda não era, a essa altura, o "collective bargaining", funcionando como instrumento de fixação das condições do trabalho; o que existia eram meros acôrdos isolados, ratificados pelas pequenas agremiações locais, ainda em organização.

Sòmente por ocasião da primeira Grande Guerra, êsses diversos pequenos agrupamentos, fundindo-se em Grandes Uniões de âmbito nacional e alta concentração de poder, começaram a exigir que as condições de trabalho nas emprêsas se estabelecessem através da troca de iáéias, em mesa-redonda de que participassem os representantes de ambas as partes interessadas.

a) Influência da Revolução Industrial.

E' decisiva a influência que os resultados mais imediatos da revolução industrial - a produção em massa, o advento da máquina, o desemprêgo, etc. - exerceram sôbre o desenvolvimento das atividades unionistas.

b) $O$ esfôrço de guerra.

A guerra mundial, por outro lado, representou papel basilar, principalmente depois que a participação dos Estados Unidos na mesma obrigou o

(4) "The chances are that there was more public knowledge about the 2,000 strikes during 1940 than about the 50,00 and more collective bargaining agreements in force during the same year, or how they developed". Ob. cit., pág. 4 .

(5) Geralmente nos acôrdos de trabalho firmados através do "collective bargaining" figuram cláusulas severas contra os movimentos de interrupção do trabalho. Alguns exempios: "no strike permissible unless or until all efforts fail to adjust the dispute" - "no strike unless with Union sanction" - "no strikes unless aproved by majority of empleyees elegible for union memberships" - "advance strike notice of from twenty-four hours to seven days", e assim por diante. 
govêrno a pesquisar os meios eficazes de garantir a normalidade da produção industrial. Em tais circunstâncias, evidentemente, as ameaças de greve assumiam caráter alarmante e se impunha a necessidade de adotar processos adequados de relações humanas no trabalho, a fim de conquistar a cooperação voluntária do operário no esfôrço da produção.

\section{c) Providências legislativas.}

O primeiro passo importante dado pelo govêrno nesse sentido consistiu na criação do "War Labor Board" cuja política,-dirigida com a preocupação de evitar, a qualquer custo, as interrupções desastrosas do trabalho na indústria pesada e de material bélico, se concretizou pelo reconhecimento das "trade unions" e o firme endôsso das aspirações do trabalhador à barganha coletiva .

Diversas leis federais se seguiram com o declarado propósito de permitir aos trabalhadores o estabelecimento de um regime de mútuo entrosamento com os empregadores na fixação das condições de trabalho.

Foi o "Railway Labor Act", de 1926, a primeira disposição legislativa a reconhecer o direito dos trabalhadores de se organizarem sindicalmente.

Pouco depois aprovou o Congresso, o conhecido diploma "Morris-La Guardia Anti-Injunction Act", que contribuiu para reforçar, de forma decisiva, as linhas mestras da legislação anterior.

Finalmente, após a crise de 1933, surgiu o "Wagner National Labor Relations Act" que deu conteúdo definitivo ao "Collective Bargaining" tornando-o, até certo ponto, obrigatório.

De então a esta parte o progresso é impressionante.

Em 1940 tínhamos nos Estados Unidos aproximadamente 60.000 acôrdos em vigor. Hoje êsse número é sem dúvida muito maior, embora a ninguém seja possível fazer indicações precisas, já que não existe qualquer obrigatoriedade de registro público dos mesmos, cujos têrmos constam apenas de documentos subscritos pelos representantes das partes contratantes, e de conhecimento exclusivo das Emprêsas e das Uniões.

\section{III - ALGUMAS NOÇÕES SÔBRE A ADMINISTRAÇÃo E CARACTERÍSTICAS MATERIAIS DOS ACÔRDOS}

As discussões em mesa-redonda, destinadas a estabelecer os acôrdos coletivos, podem ser consideradas como o primeiro passo de uma longa caminhada que deverão realizar juntos empregados e empregadores para a administração dos "collective bargainings". As negociações iniciais são o prólogo de trabalho árduo, mas quase sempre fecundo.

Êsses acôrdos, firmados como resultado de exaustivas discussões, concessões de parte a parte, acêrto de pontos de vista, assemelham-se a uma lei, cuja execução ao longo do tempo exige estudo, interpretações e emendas. Controvérsias, desentendimentos, violações voluntárias ou casuais, freqüentemente a tumultuam, determinando revisão e ajustamentos. Todos os acôrdos demandam trabalho constante de adaptação às condições supervenientes. 
Para ficarmos num só exemplo, digamos que através do "collective bargaining" hajam acordado, trabalhadores e empregadores, em que o regime ideal de promoções deva basear-se na estrita consideração do merecimento. Admitamos que reconheçam, ao mesmo tempo, as partes contratantes, que os sistemas de apuração do merecimento são demasiado subjetivos e falhos, motivo por que decidem que as promoções sejam feitas pelo critério da antiguidade até que se possam formular métodos reconhecidamente eficazes de verificação do mérito funcional.

Suponhamos, agora, que novos métodos de apuração tenham sido imaginados e propostos, capazes de satisfazer os interêsses mútuos dos contratantes. Torna-se necessária a adaptação dos entendimentos antes formulados, de modo a conformá-los às técnicas que daí por diante deverão prevalecer no tratamento das promoções.

Assim, os progressos alcançados nos diversos setores da administração de pessoal - classificação de cargos, avaliação de cargos, apuração do merecimento - forçosamente determinam a alteração das condiçõos normais de trabalho. O contrário disto seria opor-se ao progresso, e não é o que desejam empregados ou empregadores.

Já se vê que uma cuidadosa e constante administração dos acôrdos coletivos de trabalho precisa ser levada a efeito, sem c que será letra morta o documento que os registra.

\section{a) Características formais dos acôrdos.}

O resultado dos entendimentos coletivos se concretiza num tratado, o qual, além de estabelecer as condições de trabalho, pormenoriza os processos recomendados para sua execução.

Assim, duas características principais geralmente figuram nos acôrdos escritos: estabelecer condições de trabalho tais que possam prevenir greves ou "lockouts" e garantir a resolução eqüitativa de quaisquer disputas que acaso possam ocorrer. (6)

Para corsecução dêsses objetivos, os acôrdos geralmente predeterminam a processualística que deverá ser seguida no arbitramento de possíveis pendências.

Embora os acôrdos coletivos não tenham necessàriamente de apresentarse em documento escrito, é quase sempre essa a forma que assumem.

A extensão material dêsses documentos não obedece a quaisquer padrões. Passando os olhos pelos diversos acôrdos publicados, verificamos que variam, desde os autênticos cćdigos, altamente pormenorizados, até as simples afirma. ções de princípios, que deixam larga margem à discrição dos contratantes no tratamento das minúcias.

Geralmente costuma-se fazer - mais por amor da nomenclatura - a classificação dos acôrdos em dois tipos: a) acôrdos administrativos (administrative agreements) que constituem sumária articulação de normas gerais e b) acôrdos legislativos (leǵislative agreements), mais minuciosos, descendo por vêzes a minudências ezaustivas.

(6) Veja-se: "New York City Carpenter-Contracter Agreement", N. York, 1941. 


\section{b) Área de cobertura.}

A área de cobertura do acôrdo é outro ponto facultativo, sôbre o qual não existem convenções. $\mathrm{Na}$ indústria norte-americana, muitas emprêsas possuem fábricas e sucursais espalhadas pràticamente por todo o país. Nesses casos, alguns acôrdos são firmados com o objetivo explícito de aplicar-se apenas a uma das unidades locais, enquanto outros envolvem tôda a organização. Há também acôrdos parciais, que objetivam disciplinar as condições de trabalho em determinadas dependências ou departamentos de uma emprêsa.

Mais interessante do que os tipos acima mencionados é o acôrdo universal, cuja tendência está aos poucos se revelando dominante, e que são elaborados entre empregados de diferentes companhias e as gerências respectivas, passando a vigorar, portanto, para um grupo de emprêsas independentes.

c) Do estabelecimento fos acôrdos.

Não existe regra geral governando a realização de acôrdos coletivos. Êles podem surgir como resultado de negociação diplomática; podem ser fruto de uma conferência entre a administração e o representante das Uniões de Trabalhadores; podem decorrer de entendimentos entre pequenos grupos de empregados convidados pela gerência para debater problemas novos. Não há, por conseguinte, calendários prèviamente estipulados, ou regulamentos de qualquer ordem.

Sempre que as duas partes entabulam entendimento sôbre condições de trabalho, ai temos o "collective bargaining".

\section{d) Interferência governamental.}

De modo geral os acôrdos escritos eliminam a necessidade de arbitragem permanente através de tribunais especiais. A interferência oficial só tem lugar quando ocorrem disputas que as partes litigantes não encontram meio de solucionar. O Govêrno norte-americano, através do U.S. Department of Labor, mantém um grupo de "comissários de conciliação", distribuídos por todo o país, cuja missão é auxiliar empregados e empregadores a resolver os conflitos sôbre a interpretação adeçuada dos acôrdos.

Essa interferência ocorre mais frequientemente quando se tem notícia de ameaça de paralisação do trabalho.

Os "comissários de conciliação" podem interferir na disputa por solicitação das partes litigantes ou por sua própria iniciativa quando entendem que a emergência está afetando, por qualquer modo, o interêsse público.

As greves e os "lockouts" são evitados, por convenção tácita ou expressa, nos períodos de guerra. Se, porém, disputas insanáveis surgirem nessas ocasiões, serão arbitradas pelo National War Labor Board.

e) Violação dos acôrdos.

A violação de quaisquer cláusulas do acôrdo por uma das partes dá, certamente, à parte prejudicada, o direito de considerá-lo revogado, e enseja a tentativa de compelir o infrator a que retorne à legalidade convencionada, através de processos drásticos, como a greve ou o "lockout". 
Isto não obstante, em quase todos os acôrdos ùltimamente firmados está estabelecido que a interrupção do trabalhc é formalmente proibida, exceto nas condições que o próprio tratado especifica.

Em alguns acôrdos tal exigência é abrandada pelo entendimento de que o recurso à greve só terá lugar após esgotadas tôdas as possibilidades de conciliação, e ainda assim mediante aviso prévio, que varia entre 24 horas e uma semana.

\section{IV - OS ACÔRDOS COLETIVOS NA ADMIMISTRAÇÃO DE SALÁRIOS}

A função dos "Collective Bargainings" tem demonstrado sua maior oportunidade no tratamento dos problemas relativos à remuneração do trabalho.

Seria difícil demonstrá-lo com maior clareza do que o fizeram os renomados autores citados, quando escreveram:

"Just as "how much is the pay"? is uppermost in the mind of a man who takes a job, so wages and rates of pay are and have been major concerns of labor unions".

Com efeito, nenhuma das numerosas demandas empreendidas pelas Unióes de Trabalhadores provocou mais sérios conflitos. Ainda quando empregados e empregadores estejam de acôrdo no que se refere ao sistema de remuneração a ser adotado - hora, peça, prêmio, bônus, etc. - a elaboração das escalas de pagamento persiste em constituir-se no pomo da discórdia.

a) Efeito das discussões sôbre salário.

Um fato, porém, do mais alto valor sócio-econômico é que as barganhas coletivas, realizadas a respeito do problema da remuneração, têm contribuído para promover a elevação da média dos salários, pelo menos entre os empregados sindicalizados, e com isso forçado os industriais a reduzir o custo da produção, a fim de permitir a majoração dos vencimentos:

"... forced the cutling of other production costs to allow for increased wages".,

- que dá lugar a uma constante pesquisa de métodos e processos de trabalho capazes de assegurar a redução das despesas.

b) Elevação do custo de vida.

Talvez por isso o "collective bargaining" tem sido freqüentemente tachado de contribuir para a elevaçào do custo de vida.

Os números destroem essa acusação. Vejamos os dados que nos fornecem, a respeito, S. T. Williamsom \& $\mathrm{H}$. Harris, em seu interessante livro citado:

"Between 1929 and 1939 hourly earnings in manufacturing rose from 50 cents to 71,6 cents an hour. The cost of living drop in the same period about $15 \%$.

Igualmente discordando daquela afirmativa diversos autores apelam para um argumento realmente elucidativo:

"as vantagens recebidas por cerfo grupo de empregados, através de algumas uniões locais, não atingirão, necessàriamente, todos os trabalhadores do país". 


\section{c) Salário e custo.}

Em última análise, o problema dos salários redunda em conflito de difícil solução, porque apresenta têrmos de um antagonismo aparentemente inconciliável: os trabalhadores sempre desejando mais dinheiro, os empregadores se empenhando em reduzir o custo da produção, de que um dos têrmos se chama salário.

As uniões de trabalhadores têm seguidamente lutado pela idéia de subordinar os padrões de remuneração à expansão da rendia nacional, o que, em outras palavras, significa ligá-lo ao incremento dá produção. Jamais se conformam, entretanto, com a recíproca, inevitável, de que os salários devam ser reduzidos quando baixa o preço dos produtos.

"When employers under the depression propose wage reductions, they almost always meet union strong objection",

escreviamos, em 1952, em trabalho apresentado à School of Political Science da American University. (7)

A respeito concluem, com maior acêrto, os autores norte-americanos a que nos vimos referindo:

"Unions do not care do recognize that the same arguments have boomeranged".

\section{d) Os sistemas de incentivo.}

A questão do estabelecimento dos sistemas de salário variável, na base da produção individual, ou "incentive-wage", não tem chegado pròpriamente a constituir motivo de conflito entre as unióes e os empregadores, zo contrário do que freqüentemente se afirma. Os trabalhadores, em princípio, aceitam o regime de incentivo funcional. O que tem realmente constituído matéria de infinđáveis divergências é o problema da fixação dos "standards" ou padrões de produção (número de peças, ou tempo de execução da tarefa).

Dada a difịculdade de fixação dêsses padrões, a grande maioria dos empregados protegidos pelos acôrdos coletivos vem sendo remunerada na base do tempo global de serviço (salário semana, salário dia, etc.). Isto não significa, entretanto, que as Uniões tenham contribuído para fazer prevalecer êsse regime. Pelo contrário, todo operário habilitado, via de regra, está de acôrdo em receber na base da produção individual, desde que se estabeleçam "mínimos" razoáveis de tempo de execução, ou númern de peças a serem produzidas.

Convenhamos, com efeito, em que a grande maioria dos cargos, na indústria, oferece séria dificuldade de remuneração em outra base que não seja a do simples salário tempo, visto que a contribuição individual é difícil de ser calculada, em certos tipos de tarefas, ou quando a capacidade de produção do indivíduo está sujeita ao rendimento da máquina com que trabalha. Nesses casos nenhum outro método pode ser com segurança estabelecido.

(7) CARNeIRo, ENNOR DE AlmeIDA - "Paper on the subject of job evaluation and wage administration", Washington, 1952. 
E' verdade, porém, e em que pêsem tais observações, que o sistema de remuneração baseado na simples unidade de tempo, independentemente da produção individual, deixa de considerar a eficiência pessoal, e contribui, de maneira alarmante, para favorecer os incompetentes, cujos salários serão os mesmos dos empregados capazes.

Nenhum incentivo ao esfôrço e aplicação pessoais se poderá extrair dêsses sistemas, onde os empregados são, de fato, remunerados com demasiada generosidade ou demasiado rigor, em relação uns com os outros.

Por isso, nos sistemas de remuneração por tempo, as Uniões de trabalhadores têm mais ou menos sistemàticamente se oposto à variação dos salários de acôrdo com a apuração da eficiência, preferindo uma uniformidade falsa, mas honesta, do que uma tentativa de avaliação individual que pode redundar em simples engôdo.

Daí resulta o quase completo abandono dos sistemas de promoção na base da apuração do merecimento, em conseqüência do que o critério da antiguidade assume impávido domínio.

A Administração das Emprêsas, por outro lado, embora reconhecendo as sólidas razões que apoiam os trabalhadores em suas pretensões, geralmente preferem os sistemas de remuneração na base de produção por peças, quando não seja por outro motivo por que fornece elementos mais seguros à estimativa do custo.

Do ponto de vista técnico, as opiniões se dividem, neste particular. O sistema de remuneração por peças tem sido evitado por algumas emprêsas, sob o fundamento de que, estimulando o operário à aceleração do trabalho, acarreta o detrimento da qualidade, a perda do material e o sacrifício da maquinaria.

Em resumo, podemos dizer que as Uniões de trabalhadores não se têm revelado definitivamente inclinadas a qualquer dos sistemas de salário conhecidos, variando as preferências de conformidade com a natureza do trabalho.

Há, entretanto, um aspecto que convém ressaltar. Nas discussões travadas entre empregados e' empregadores a respeito do problema da remuneração, as emprêsas têm sempre insistido em que lhes seja assegurado o direito de escolher o sistema que preferem.

A maioria dos acôrdos formulados através do "Collective Bargaining" estabelece, com pormenores, os métodos que deverão ser seguidos na fixação dos niveis de remuneração, quando não incorporam, prèviamente, a indicação dos mesmos.

O mais freqüente ponto de discordância, entretanto, ocorre quando se tem em mira estabelecer sistemas de salários pelo processo de bonificações ou participação (profit-sharing), que exige do operário, para fazer jus às vantagens prometidas, que exceda um "standard" mínimo de produção, convencionado.

Sãn sistomac mistos, que ccmbinam o salário peça, ao salário tempo, estabelecendo a remuneração em base dupla, e toma como elemento de cálculo a produção quantitativa e o tempo para tal consumido pelo operário.

O sistema teve os seus primórdios há cêrca de um século, através do "premium plan", então preconizado por Halsey. Mais tarde, a título de aper- 
feiçoamento, apareceu o método Taylor (Taylor's differential piece plan), seguido das alterações introduzidas pelo "Merrick plan". As tentativas, todavia, não pararam aí e se fizeram seguir das contribuições de Gannt, Emerson, Bedaux, Haynes-Monit e muitos outros.

Qualquer dêstes planos depende, essencialmente, de rigorosa contabilidade do custo, meticulosa análise dos cargos e profundos estudos de tempos e movimentos.

A necessidade de medição acurada - a despeito dos progressos científicos que se têm realizado nesse terreno - parece com efeito não ter sido compreeñdida pelo trabalhador médio, para quem tais complicações despertam invencível ansiedade e suspeita.

Por isso a maioria dos empregados dêles desconfia e thes nega cooperação. Não obstante, pròximamente $25 \%$ das grandes indústrias manufatureiras norte-americanas operam sob algum dos vários sistemas dessa categoria.

$$
\mathrm{V} \text { - CONCLUSÃo }
$$

"Collective Bargaining" é, na realidade, mais do que um simples meio de obter altos salários e condições confortáveis de trabalho. E' um dos mais importantes instrumentos de política de pessoal jamais ensaiado, e que se tem revelado inteiramente satisfatório para assegurar e manter a desejável cooperação entre empregado e empregador, estimulando as atividades produtivas, num verdadeiro afã democrático.

Não fôsse isto exato, e não teríamos em 1941, nos Estados Unidos da América, 11 milhões de operários - pràticamente $1 / 4$ da população obreira - trabalhando sob condiçóes estipuladas através de "Collective Bargaining Agreements". (4)

Os empregados desejam ser reconhecidos como sêres humanos e não como máquinas de produção em série. Desejam, sobretudo, que se thes compreenda o comportamento psicolćgico, e se thes respeitem os anseios de confôrto e de progresso.

Uma sadia política de pessoal precisa considerar essas verdades e valerse delas para inculcar nos trabalhadores verdadeiro espírito de equipe, obtendo do empregado confiança e orgulho no trabalho, fatôres que fatalmente conduzem à lealdade, à cooperação desinteressada, e ao entusiasmo, sem o que não haverá obra possível.

\section{SUMMARY}

Collective bargaining defined as an instrument of sound industrial relations, not metely as a maans for obtaining better wages or more satisfactory workin conditions. Peaceful conditions as (1) the result of collective bargaining and (2) the influence of labour unions. The seneral public usually not aware of the beneficial outcome of such agreements, but rather attentive to the rare instances of crisis. Collective bargaining versus strikes as regards claims fo- higher salaries. Day-by-day adjustments and revisions of collective bargुains as a necessity. Agreements to be adapted to changing conditions. Scope and formal aspects of collective bargain agreements discussed. The U.S. Dept. of Labor commissioners of conciliation and their role. Wage schedules as the strongest point of disagreement between employers and employees. Collective bargaining as a factor of wages increase; its being charged of raising the cost of living not a fact. Time-wages and incentive-wages analyzed. Incentive bonuses of profit-shating plans as a debatable issue. Col'ective bargaining in personnel administration as an expression of wise policy. 